\title{
Prof. Rhoton: Master and Mentor
}

\author{
Juan C. Fernandez-Miranda 1,2,3 \\ ${ }^{1}$ Department of Neurosurgery and Otolaryngology, University of \\ Pittsburgh Medical Center, Pittsburgh, Pennsylvania, United States \\ ${ }^{2}$ Center for Cranial Base Surgery, University of Pittsburgh Medical \\ Center, Pittsburgh, Pennsylvania, United States \\ ${ }^{3}$ Surgical Neuroanatomy Lab, University of Pittsburgh Medical Center, \\ Pittsburgh, Pennsylvania, United States
}

J Neurol Surg B 2016;77:288-290.

It is with great sorrow, but profound gratitude that I write these words in remembrance of Prof. Albert L. Rhoton Jr. Using his own expression, not in my wildest dreams I could have imagined working closely with him, one of the greatest medical souls that have ever lived. I had the unique privilege of spending two extraordinary years in his laboratory, and here, a decade later, I would like to illustrate what it was like and what it meant to be his fellow.

Prof. Rhoton established his microneuroanatomy laboratory at Mayo Clinic in the late 1960s, as he would say "not to write a paper, but to improve the life of my patients." In 1974, he created his microsurgery education center at the University of Florida, with a missionary leitmotiv: "Every Second of Every Day," he wanted to train and teach enough surgeons in microsurgical neuroanatomy and techniques so that there would be someone having surgery during every second of every day that was being made better because of his influence (- Fig. 1). After 42 years with more than 100 fellows, more than 500 scientific articles, and thousands of lectures later, there is no question he has accomplished that goal: patients all over the world will continue benefiting from Prof. Rhoton's work forever.

When I started training in Prof. Rhoton's laboratory in 2005 , he was a living legend, the father of microsurgical neuroanatomy, and mentor for many world-class neurosurgeons (-Fig. 2). I remember vividly the initial meeting in his office to discuss the goals for my fellowship, and there I felt for the first time his magic aura of love and kindness that would irradiate and comfort everyone around-like the giant oak that gives shadow and protects from the bright sun. "Other than working in the lab, you may want to visit Florida's coast and Disneyworld with your wife," he said with that smile that would illuminate your soul. We had sold everything we had back in Spain to fund our stay and work in Prof. Rhoton's laboratory looking for microsurgical training and anatomical knowledge, and we found so much more. Since then, every single second we spent with him and his family was unique and special. All fellows and families particularly enjoyed those pizza parties at Rhoton's that Mrs. Joyce Rhoton organized to
Address for correspondence Juan C. Fernandez-Miranda, MD, Department of Neurological Surgery, UPMC Presbyterian, Suite B-400, 200 Lothrop Street, Pittsburgh, PA 15213, United States (e-mail: fernandezmirandajc@upmc.edu).

celebrate every fellow graduation ( - Fig. 3). Dr. Rhoton was a devoted family man and he tremendously enjoyed being around and playing with children (-Fig. 4). Joyce, his wife for 58 years, is the great woman behind the great man. Her dedication and support, always by his side, is a key aspect of Prof. Rhoton's successful biography (-Fig. 5).

The working philosophy in the laboratory was defined by Prof. Rhoton's description of the brain as the crown jewel of creation and his quest for beauty and perfection. I attended my first days in the laboratory observing with astonishment the exquisite dissections that the fellows were performing. I found out then that those extremely beautiful and unreal

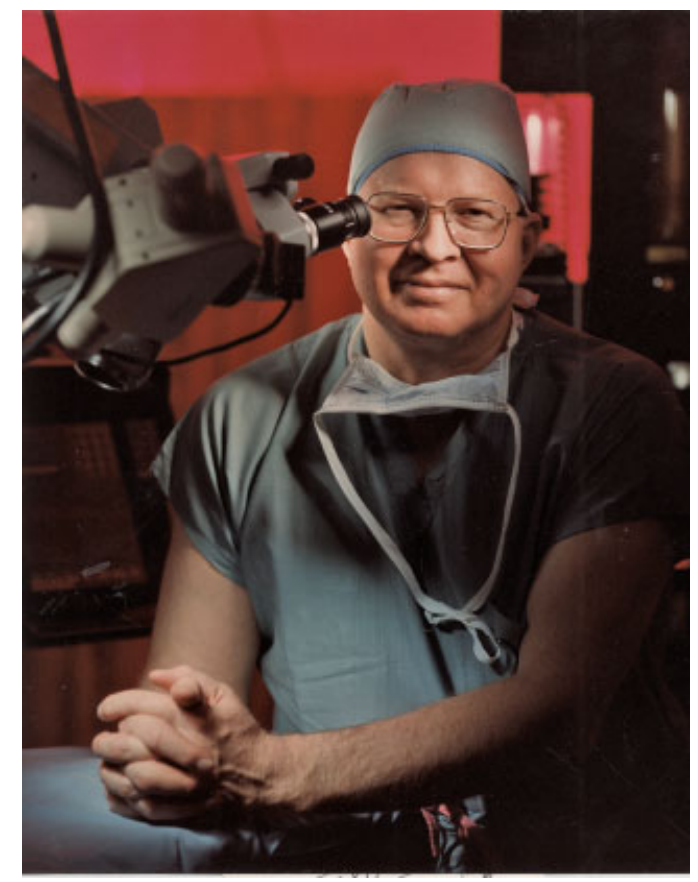

Fig. 1 Prof. Rhoton in 1989 at the Shands Hospital of the University of Florida. (c) 2016 Georg Thieme Verlag KG Stuttgart · New York
DOI http://dx.doi.org/ $10.1055 / \mathrm{s}-0036-1584945$. ISSN 2193-6331. 


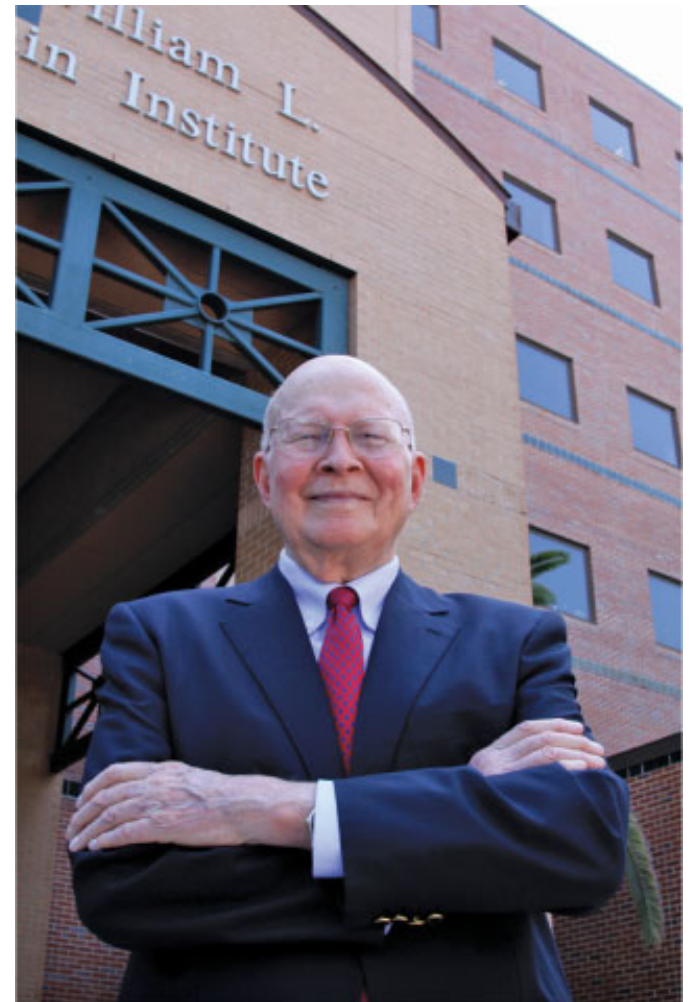

Fig. 2 Prof. Rhoton in 2010 at the entrance of the McKnight Brain Institute of the University of Florida.

pictures from his articles and books were actually real and they were being crafted right there in front of me. The laboratory was filled with mysticism and stoicism, as we would spend countless hours, days, weeks, aiming to create an anatomical piece of work worthy of Prof. Rhoton's appreciation. At the beginning, we did not fully understand the importance of accurate and meticulous dissections, but early on Dr. Rhoton would clearly explain: "We want perfect anatomical dissections, because we want perfect surgical operations," he wanted us to create the perfect anatomical pictures that would replicate a perfect surgical approach, step

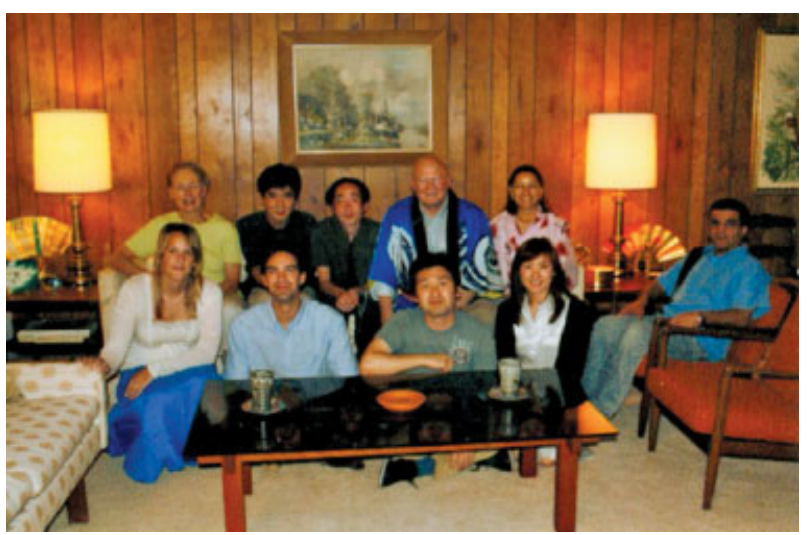

Fig. 3 Fellow graduation party at Rhoton's in 2006. Note that Dr. Rhoton and Ms. Laura Dickinson, his personal assistant, are both wearing Japanese kimonos.

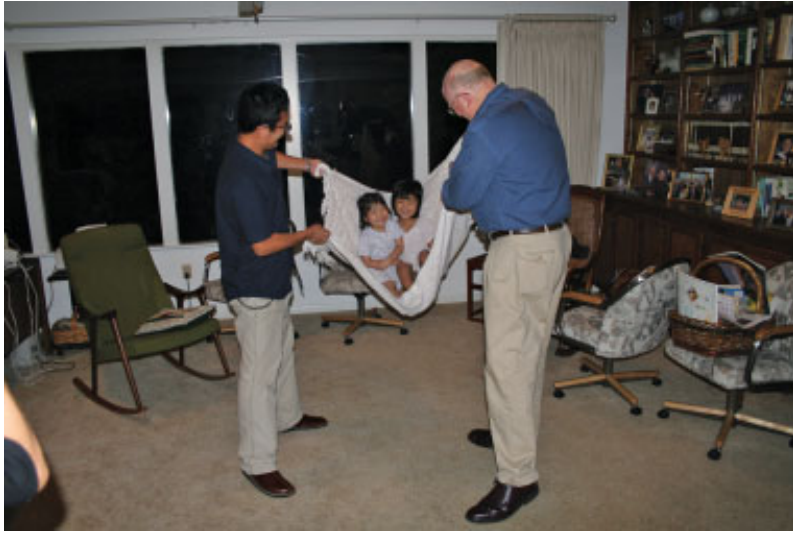

Fig. 4 Dr. Rhoton rocking two little Japanese girls with a blanket during a pizza party.

by step, layer by layer. We then understood that a precisely done microdissection, where our brains would invest many hours and days studying and imprinting every single anatomical structure and their spatial relationships, is worth more than several repeated dissections done not so diligently. Even more, we realized that Prof. Rhoton was always looking to supplement his already precious collection of anatomical dissections with yet another elegant three-dimensional view of a certain anatomical region that he could use to teach the intricate beauty of microsurgical neuroanatomy to the next privileged audience, eagerly waiting to learn from him in any corner of the neurosurgical world. He would, in fact, welcome any new additions to his collection as a kid would with a new toy, with such great joy that would make every effort truly worthwhile (-Fig. 6).

His primary goal was not to write articles, but to train microneurosurgeons (-Fig. 7). However, early on his

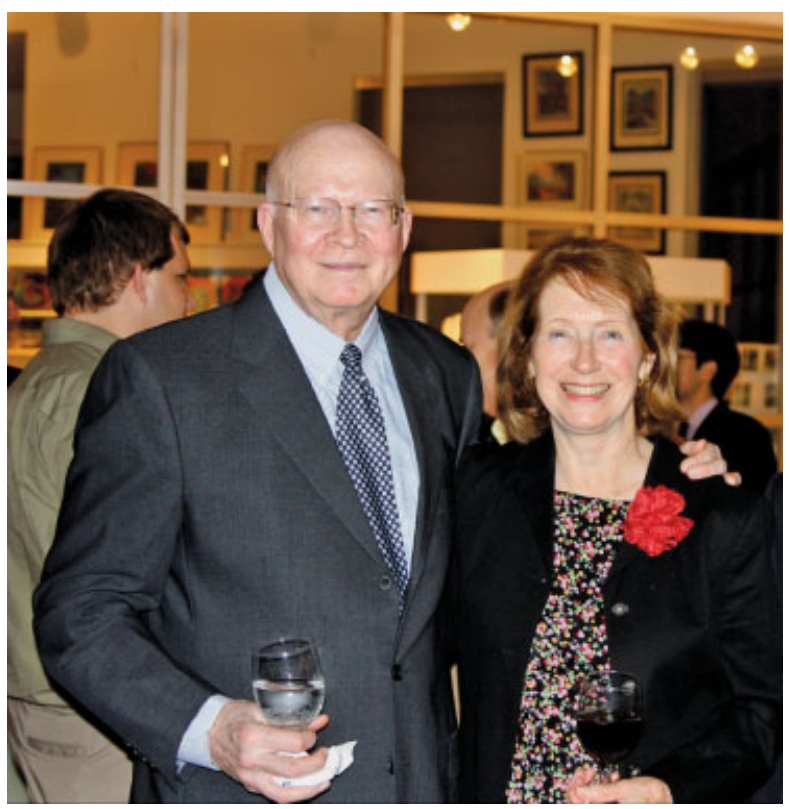

Fig. 5 Dr. and Mrs. Rhoton in 2008 


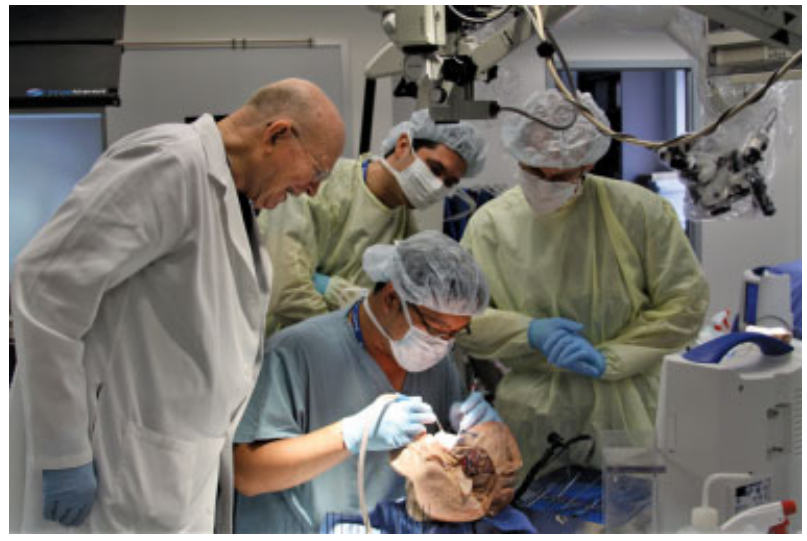

Fig. 6 Prof. Rhoton enjoying an anatomical dissection during a microneurosurgery course at the University of Florida Brain Institute.

career, he realized the wide impact his articles would have in the development of microneurosurgery. Thereafter, he would consistently work on one article after the other, redefining surgical approaches and classifying anatomical regions from a microsurgical point of view to cover the vast majority of cranial surgery and anatomy. I watched him many times working patiently over and over again on the same projects and paying close attention to every little detail from labeling pictures to editing articles written by fellows with English as a second language. The beauty and perfection of the pictures he used for his articles, were just an extension of his own beauty and perfection. His monumental work is a fundamental masterpiece of contemporary neurosurgery and we should all try to stand on his shoulders to continue his work in our own way as neurosurgery continues evolving.

His role and his influence in neurosurgery have been appropriately compared with that of Lorenzo de Medicis

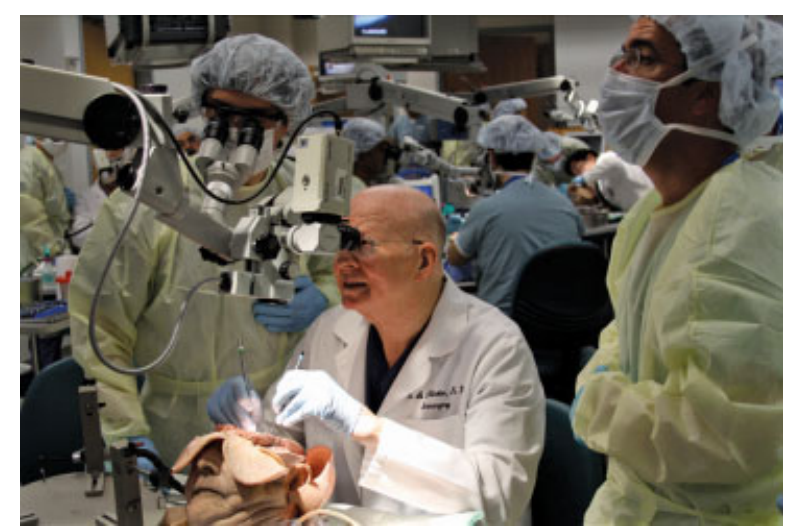

Fig. 7 Prof. Rhoton teaching and using his microdissectors during a microneurosurgery course at the University of Florida Brain Institute.

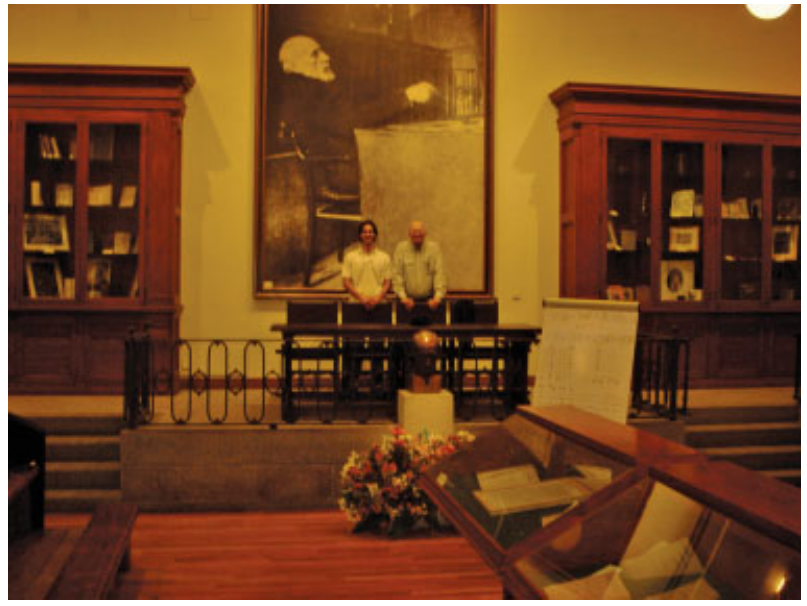

Fig. 8 Prof. Rhoton at the Ramon y Cajal Museum (Madrid, Spain 2006).

during the Renaissance of Arts in Florence, Italy, since both were directly responsible for an extraordinary development of their respective fields. We could also propose a comparison to Santiago Ramon Y Cajal, Spanish physician scientist and father of Neuroscience, because both employed tenacious work and creative art to develop a whole new field and their own school of artistic science (-Fig. 8). We could go beyond and compare Prof. Rhoton with a fictional personage such as Master Yoda, since both were masters of competence and compassion, and the most respected leaders in their respective worlds; their main difference is that Dr. Rhoton actually existed.

Dr. Rhoton would always look at the bright good side of things, always positive, encouraging us to be and do our best. He made us better by being at his side. I never heard him complaining or criticizing anyone or anything. Even in situations that were clearly not fair and would irritate anybody, his greatness was always way above and beyond. Negative feelings, complaints, aggravations, those were for the common people, definitely not for him. Once he confidently told me, as if it were a secret, his Kantian ethic maxim: "Juan, you know, it is good to behave in a way that makes everybody around want you to succeed, from the cleaning lady that visits the office daily, to your neurosurgery associates." This teaching, too, remains with me every day, as I realize how difficult it is to emulate my mentor.

Prof. Rhoton left us the way he lived: working until the end with a smile on his face-working on an article on Friday, doing his taxes on Saturday, and going to sleep, forever, on Sunday. He will always live in our minds and souls to teach us once again that competence and compassion should guide our profession, which we need to keep working hard, go to the laboratory to train ourselves and others, be gentle, safe, and accurate in the operating room, and practice love and kindness with our patients. 